the indications for introducing plenty of saline are clear.

It is to the prevention of shock that we must look with hope and some degree of confidence for the future. No doubt Professor Crile's anoci-association methods are on the right lines, but to use his native country's expression, he has not quite " got there" yet. For instance, Case 10 in Table II. died from severe and typical shock in spite of a long time spent in thoroughly injecting the abdominal wall with novocain and the peritoneal surfaces with quinine-urea-HCl before cutting. Moreover, quinine-urea-HCl is destructive to the tissues, and we urgently require a drug which will be long-lasting in its effect without causing necrosis On the other hand, in some of the writer's own abdominal cases it has worked like a charm, abolishing both shock and after-discomfort. The method is novel and can probably be improved in its details, and in blocking the up-paths of painful stimuli, as far as we can now see, lies the hope of the future. That problem once solved, we should be able to operate on desperate cases without that fear of death on the table or within a day or two which at present forms the barrier against the emancipation of surgery to do its beneficent work unhindered.

The present lecture is as a scout sent forth to survey the barrier, and a scout's difficult ambition is to tell a tale which the future will prove true.

My very best thanks are due to my surgical colleagues at the Bristol Royal Infirmary for allowing me to make use of their cases, also to Professor A. F. Stanley Kent, Dr. J. R. Kay-Mouat, Mr. G. Scott Williamson, and Mr. Scott White for kind help. The expenses of the research were assisted by the University of Bristol Colston Research Fund.

References.-A, Major.-Crile: Surgical Shock, 1897 ; Blood Pressure in Surgery; and Trajor.-Crile : Surgical Shock, 1897 ; Blood Pressure 1910, vol. xxviii., p. 553. Crile and Dolley : Tournal of Medical Research Boston, 1909, vol. xx., p. 275. Crile: THE LANCET, vol. ii.. 1913 Boston, 1909, vol XX., p. 275. Crile: THE LANCET, vol. ii.. 1913.
Mummery: THE LANCET, 1905, vol. i., pp. 696, 776, 846. Yandell Mummery: THE LANCET, 1905, vol. i., pp. 696, 776, 846. Yandell Henderson : American Journal of Physiology, many papers, 1908-11. Cobbett: Allbutt's System of Medicine, first edition, vol. iii., p. 320, article Shock. Vale: Medical Record, New York, 1904, vol. lxvi., p. 325.
pædia of Minor, -1 . Mansell Moullin: International Encyclo-
Shery, pæedia of Surgery, 1882. 2. Groeningen : Ueber den Shock, Cheyne: Treves's System of Surgery, vol. i., article Shock, p. 153 4. Malcolm: THE LANCET. 1905, vol. ii., p. 573. 5. Malcolm: MedícoChirurgical Transactions, 1907, vol xe., p. 563. Malcolm: Clinical Journal, 1909, vol. xxxiv., p. 328. 7. Seelig and Lyon : Journal of the American Medical Association, 1909, vol. lii,, p. 45. 8. Seelig and Iyon: Surgery, Gynæcology, and Obstetrics, 1910, vol. xi., p. 146 9. Porter and Quinby: American Journal of Physiology, 1907, vol. xx.. pp. 444, 500. io. Tyrrell Gray and Parsons : Brit. Med. Jour., 1912, vol. ii., pp. 938, 1004, 1065, 1120. 11. Boise : American Journal of Obstetrics, 1907, vol. lv., pp. 1, 95. 12. Rendle Short: New Physiology in Surgical and General Practice. Second edition, p. 14. 13. Rendle Short: British Journal of Surgery 1913, vol. i., p. 114. 14. Sherrington and Copeman : Journal of Physio logy, 1893, vol. xiv., p. 52. 15. Sherrington: Proceedings of the Roya Society, 1894, vol.'1v., p. 161. 16. Levy: Proceedings of the Roya Society, vol. lxxi., p.171. 17. Douglas: Middlesex Hospital Cancer Reports, 19C4. p. 100. 18. Elliott: Journal of Physiology, 1912, vol. xliv., p. 374. 19. Von Anrep: Journal of Physiology, 1912. vol. xlv. p. 318. 20. Bainbridge and Parkinson: THE LANCET, 1907, vol. i., p. 1296. 21. Levy: Heart, 1913, vol. iv p 342 . 22. O. B. Meyer: Zeitschrift für Biologie, 1906, 48, p. 352. 23. Battelli ; Comptes Rendus Biol., 1902. July, p. 928. 24. Cevidalli and Leoncini : Lo Sperimentale, $1909, p .175 .25$. Sherrington : Integrative Action of Nervous System, p. 240. 26. Thiele: Journal of Physiology, 1905, vol. xxxii., p. 358 . p. 1. 28. Seelig, Tierney, and Rosenbaugh: American Journal of Medical Sciences, 1913, August, p. 195.

Children's Home at Exeter.-On Feb. $23 \mathrm{rd}$ the new home which the Exeter board of guardians have erected for children who were formerly resident in the workhouse was formally opened. The building is situated close to the workhouse at Heavitree, but quite separate from that institution. The cost is about $£ 6500$, and it will provide accommodation for 30 girls and 41 boys, with rooms for four attendants.

\section{THE AGGLUTINATION OF M. MELITENSIS} BY NORMAL COW' MILK.'

\author{
BY P. W. BASSETT-SMITH, C.B., M.R.C.S. ENG., \\ M.R.C.P. LoND., \\ FLEET-SURGEON, R.N. ; LECTURER ON TROPICAL MEDICINE,
} ROYAI NAYAL COLLEGE, GREENWICH.

THE fact that the milk from cows in London is in some cases able to cause agglutination of the M. melitensis has lately been brought forward by Kennedy. He found a positive reaction with the milk of 3 out of 22 cows, and 5 times from mixed milks. The reaction was also obtained when using whey, but was diminished or altogether lost by filtering the milk through a Berkefeld or Doulton candle.

Anomalous reactions have frequently been described when examining goats' milk. In Malta Martel, Tannon, and Cretien state that as a means of diagnosis it is unreliable. In Algiers and Tunis in the laboratories of Sergent and Nicolle the importance of these lacto-reactions is highly rated, and Zammit carries out a very large number daily at Malta. Cows in the endemic area have been frequently noted by means of lacto-reactions as being infected, but I think no one depends upon it wholly for diagnosis.

It appears to be of the utmost importance to recognise that the reaction is a specific one, and that by its means an enormous amount of public health work for prevention of the spread of undulant fever is possible. It therefore renders it necessary to find out what error of technique has been committed to give rise to these misleading results. For two months $I$ have been testing milks with this object without much success, but some of the reactions are so unexpected that I have ventured to bring them forward.

I first tested 16 samples of milk from separate cows with five different strains of M. melitensis at 1 in 2 dilution both microscopically and by sedimentation. Some strains were found to agglutinate much more easily than others. The type strain originally obtained from Wright at Netley acted best, the emulsion being made from a culture not more than 48 hours old. This was always controlled by specimens without serum, with normal serum, and with immune serum. A further series of samples from 21 other cows was obtained from two farms near. Besides these, 32 samples of mixed milks obtained from different dairies have been tested. A total of 69 samples.

I found that boiling the milk cut out all the reactions; that heating it to $60^{\circ} \mathrm{C}$. for half an hour cut out some, but not all. That with the unheated milk of 37 individual cows-tested with equal parts of emulsion made with normal saline solution3 reacted in $\frac{1}{2}$ hour, 6 in 1 hour, and 6 by sedimentation; these were reduced to 2,4 , and 5 by heating the milk. (Table I.) In dilution of 1 in 20 of milk direct from the 21 cows I did not get any positive reactions either microscopically in 1 hour or by sedimentation with heated or unheated samples.

Of 32 samples of mixed unheated milks tested with equal parts of emulsion made with saline solution, 5 gave positive reactions in $\frac{1}{2}$ hour microscopically and 11 by sedimentation. In dilution of

1 Published by permission of the Medical Director-General of the Royal Navy. 
1 in 20 there were 9 positives in one hour and 11 by sedimentation. (Table II.)

I noticed that frequently with the mixed milks the reaction was more strongly marked in those

TABLE I.-Milk from Individual Cows in London. 1 in 2 dilution.

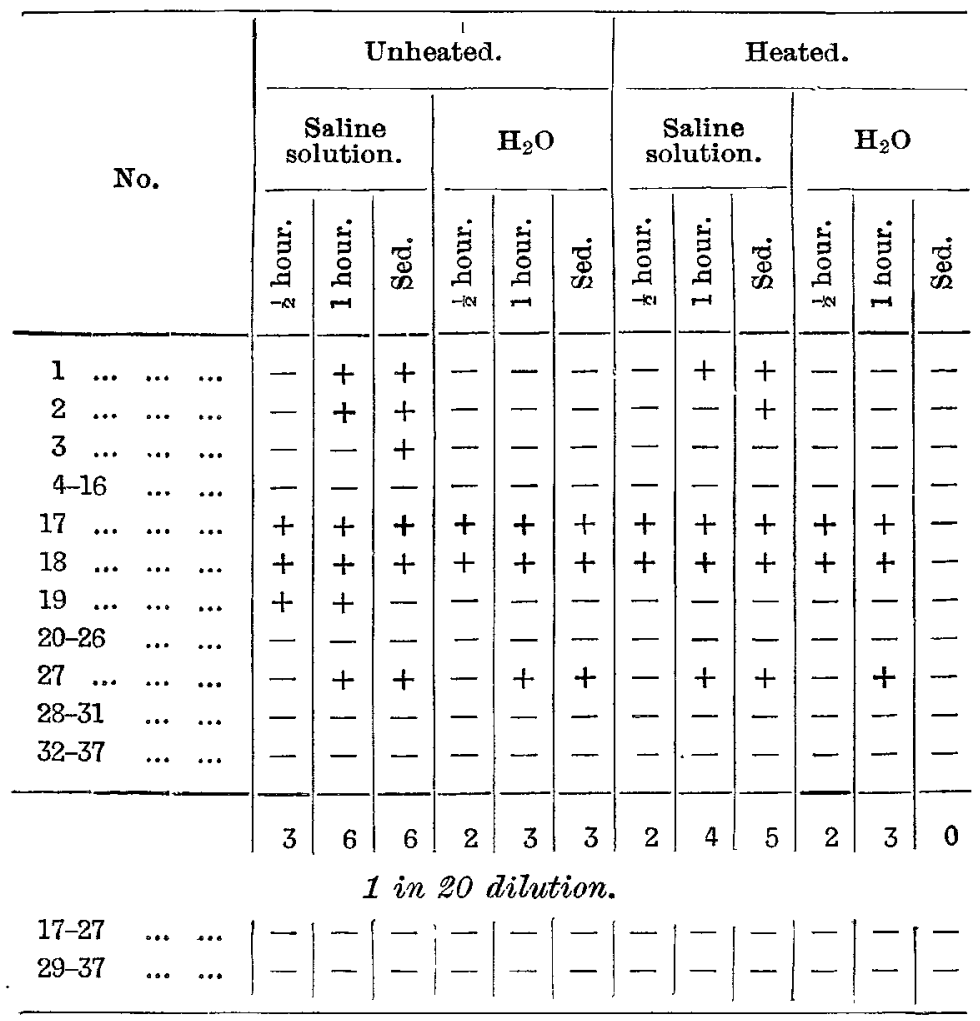

TABLE II.-Mixed Milk from Different Dairies in London.

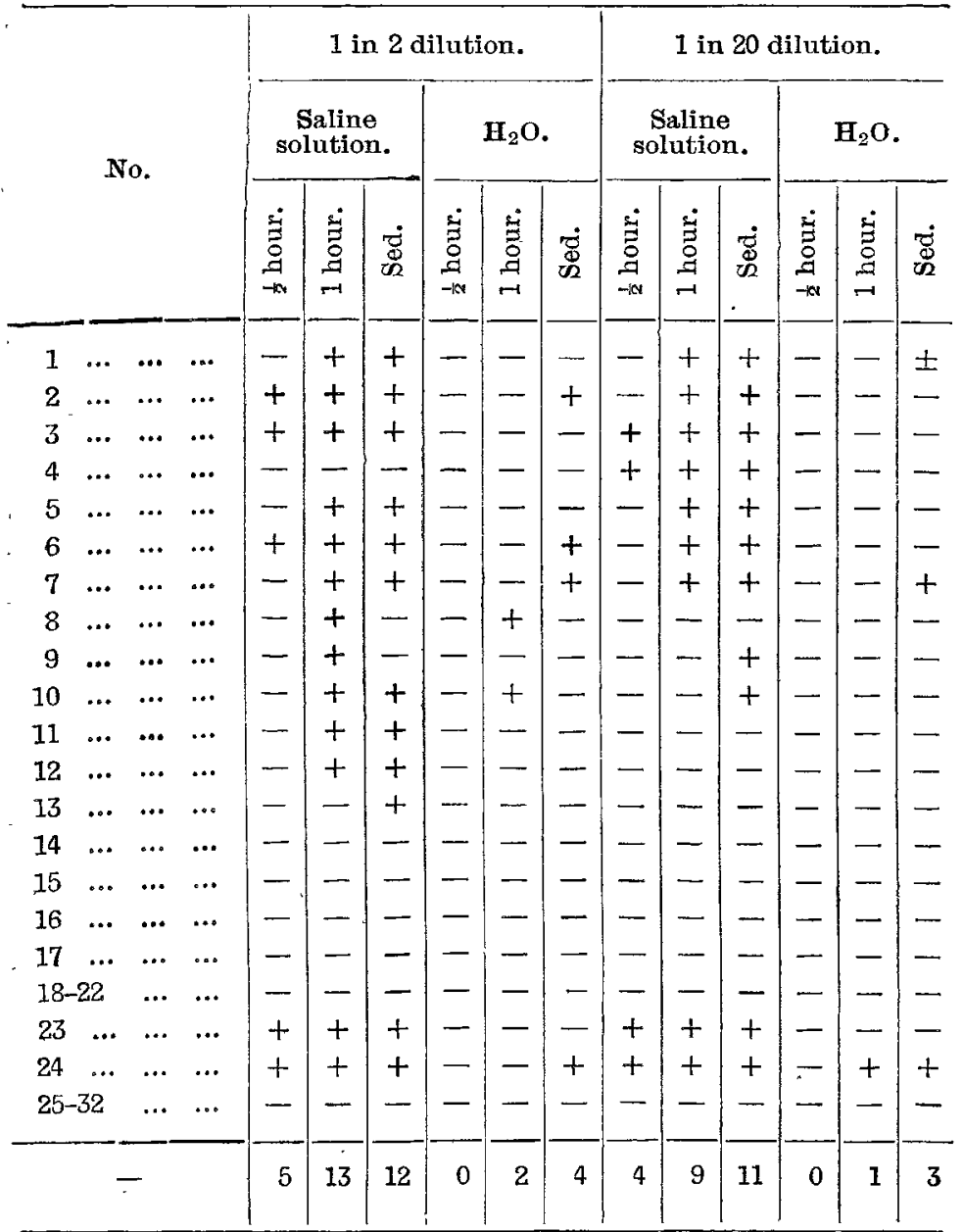

Heating cut out reactions of Nos. 23 and 24

Nos. 7 and 23 agglutinated with saline solution up to 1 in 100 and up to 1 in 20 with $\mathrm{HO}$ that were diluted to 1 in 20 than in the low dilu. tions. I thought that it might be the diluting fluid at fault. Similar specimens were therefore put up with saline and distilled water, and examined microscopically and macroscopically with heated and un. heated milks at 1 in 2 and 1 in 20 dilutions. 32 mixed samples were thus tested and the reduction of the positive reactions with the distilled water was very marked-12 to 4 , both emulsions agglutinating well the immune serum control. With the 1 in 20 dilution of milk the positives were reduced from 11 to a doubtful 3. The highest reaction obtained was 1 in 100 with mixed milk, which did not rise higher than 1 in 20 with water dilution.

When the milk is kept the reactions may quickly change, as shown in Table III. A sample of unheated

TABLE III.-Milk Direct from Cow No. 4. First day : Unheated.

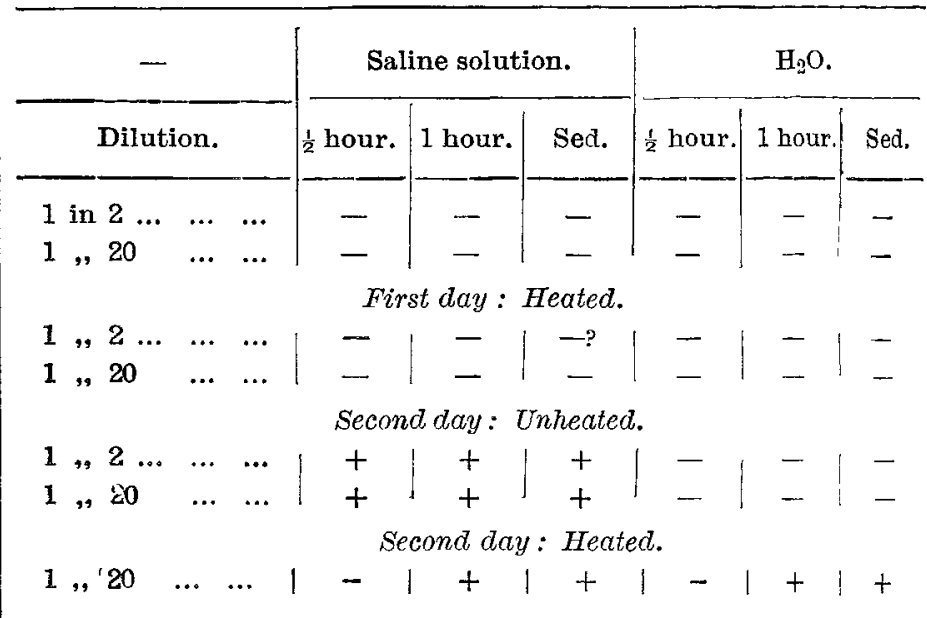

Showing change in reaction for time.

milk taken direct from a cow gave complete negative reactions to all the tests, but 38 hours after the dilutions with saline were all positive up to 1 ir 20 , but still remained negative with the water dilutions. Heated samples gave complete positive reactions after that time.

Five samples from individual cows which had given positive reactions in low dilutions were plated out for isolation of M. melitensis but without success. I was unable to obtain a sample of serum for testing, but all the cows were stated to be in perfect health.

In Malta the milk is tested direct in a dilution of 1 in 20 , using saline solution, and observing by the sedimentation method only. In the last return 50 per cent. of the goats so tested gave a positive reaction, which is possibly too high, but the result is always controlled by a serum reaction before the animal is considered to be infected. In Algiers and Tunis a dilution of 1 in 30 is used, the specimen being examined both microscopically and by sedimentation methods fol six hours.

Result.-Using a 48. hours' culture for the emulsion and a dilution of 1 in 20 in this series, none of the milk from 21 cows gave a positire reaction when examined quite fresh, but with mixed samples of milk a high proportion reacted positively at this dilution, most of which were cut out by using heated milk and diluting with distilled water instead of saline solution. In any case it is very necessary to centrifuge the milk rely thoroughly and to examine it at once, using an emulsion made from the $M$. melitensis not more than 48 hours old, and even then a few errors will 
occur by false clumps in the sedimentation tubes carrying down micrococci with them.

There is no doubt that cows' milk in some cases has a natural tendency to agglutinate the M. melitensis, but if care is taken most of these nonspecific reactions may be avoided. The reaction always requires to be controlled by other methods of diagnosis before an animal can be considered to be infected.

\section{A CASE OF TRANSGASTRIC EXCISION OF A GASTRO-JEJUNAL ULCER.}

By Sir BERKELEY G. A. MOYNIHAN, F.R.C.S. ENG., PROFESSOR OF CLINICAI, SURGERY IN THE UNIVERSITY OF LEEDS, AND SURGEON TO THE LEEDS GENERAI INFIRMARY;

$$
\text { AND }
$$

E. TISSINGTON TATLOW, B.A., B.CH., M.D. (T.C. Dub.).

THE operative treatment of a peptic jejunal or gastro-jejunal ulcer following a gastro-enterostomy is beset with many technical difficulties. This is notably true in cases where the original anastomosis has been of the posterior no-loop variety, and where in consequence the ulcer is somewhat inaccessible.

The usual procedure in operating for this type of ulcer is to resect the whole of the jejunal length engaged in the anastomosis, and also the adjacent portion of the stomach; and after this to make a new junction between the stomach and the jejunum. It is obvious that in a case where a posterior no-loop operation has been performed this resection of the entire anastomosis is exceedingly difficult, often indeed impossible; and even in the cases where it is possible a modified anterior Roux operation in " $Y$ " has usually to be performed after the resecfion, the making of a second posterior anastomosis being an impossibility.

The method of transgastric resection for such cases of jejunal ulcer was suggested by Moynihan ${ }^{1}$ in 1912, but the operation was not performed by him previously to this operation, the notes of which are given below, nor are we aware of any other surgeon having recorded a similar case.

The patient, a male aged 47, had a history of abdominal trouble extending over seven years. At the commencement his only symptom was epigastric pain on kneeling, on leaning forward, in fact, after any movement which caused contraction of his recti abdominis. Gradually this pain became more severe, occurring at almost regular intervals, independently of movement, and accompanied by flatulence and hyperacidity. The pain was of the variety known as "hunger pain," commencing from two to three hours after meals, and being relieved by lying down or taking food. There was never any romiting. The site of the pain was above and to the right of the umbilicus. At first this pain was only felt at intervals; gradually, however, the intervals became shorter and the periods of pain longer. After three and a half years of this the patient had a sudden attack of severe abdominal pain in the right hypochondrium, which was diagnosed as a subacute perforation; from this attack he recovered without operation. In January, 1912, a posterior gastro-enterostomy was performed by another surgeon. The patient recovered from this operation, and his symptoms subsided only to return about eight months later. The pain after this was lower in the abdomen and more to the

1 Duodenal Ulcer, 1912, p. 204. left than previously, and was really the only symptom he had; but this pain was severe in character, and for the last few weeks before admission to the nursing home almost constant in duration.

Dr. L. A. Rowden's X ray report was as follows:"The bismuth feed passes freely through the csophagus. The stomach is not dilated. The outline is regular except for an indentation about the middle of the greater curvature. Peristalsis is seen, but it is not excessive. The gastro-enterostomy opening is patent; as far as I can judge about twothirds of the food passes through it and about onethird through the pylorus. The stomach is empty two hours after the meal. No food lodges in the duodenum nor is there any duodenal kinking. The small intestine is empty in 12 hours. No stasis. No ileal kink. In 24 hours almost all the bismuth has been passed per rectum. I have seen no abnormality in the large intestine. There is no $\mathrm{X}$ ray evidence of calculus in either kidney, in the ureters, or in the bladder."

On Jan. 7th, 1914, the abdomen was reopened by Sir Berkeley Moynihan and the notes which follow are by Dr. Tatlow, who assisted at the operation. The scar of the previous operation was excised and for the deeper portions of the incision Crile's anæsthesia was adopted. The transverse colon, which presented in the wound, was markedly hypertrophied and distended and also kinked in a very curious fashion-its middle

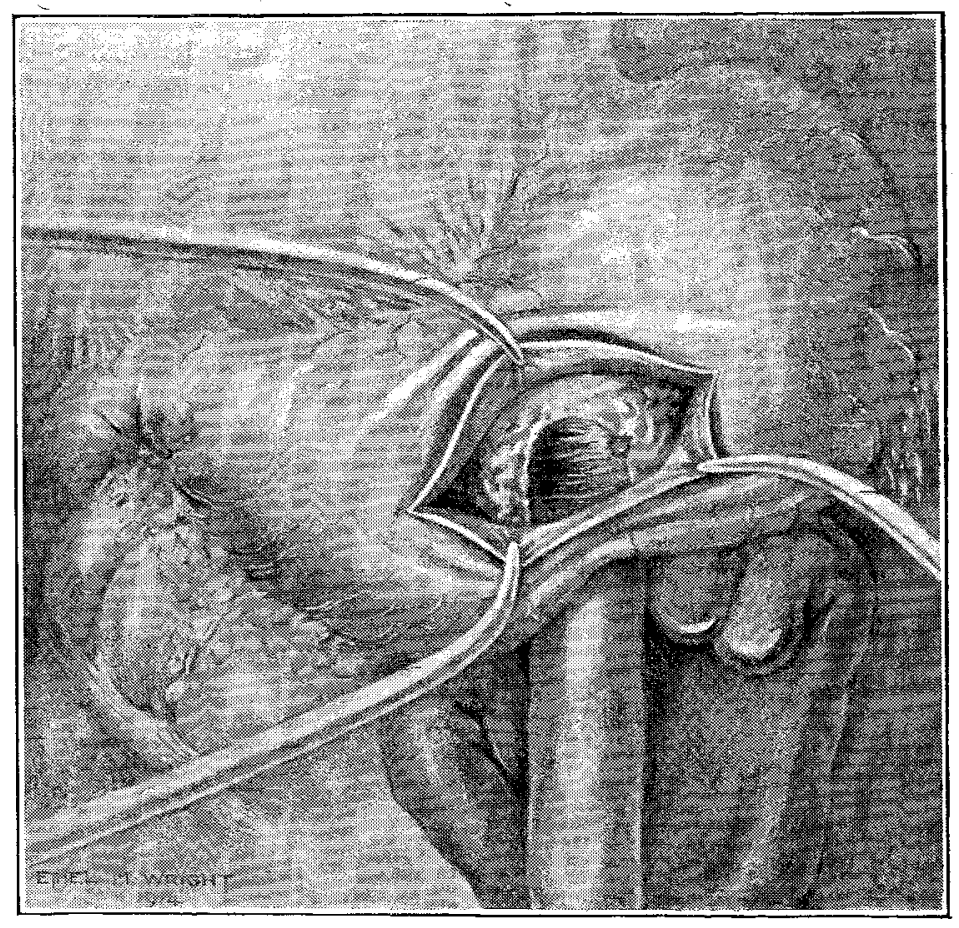

Transgastric excision of a gastro-jejunal ulcer following gastroenterostomy.

portion being adherent to the under surface of the left lobe of the liver and to the diaphragm. Before the stomach could be examined it was necessary to separate the adhesions fixing the colon in this unusual position. This separation was exceedingly difficult owing to the inaccessibility of the parts. The stomach itself was normal in outline, but there was a scar of an old ulcer on the anterior surface of the first stage of the duodenum. The anastomosis which had been performed was a posterior, vertical, no-loop gastro-enterostomy. The stoma was of adequate size and in the correct position. On feeling the stoma with the finger a 